Published in International business research, August 2016, vol. 9, no. 8, pp.24-36 which should be cited to refer to this work

\title{
A Matter of Love: Exploring What Enables Work-family Enrichment
}

\author{
Sowon $\mathrm{Kim}^{1}$, Mireia las Heras ${ }^{2}$, Maria Jose Bosch ${ }^{3}$ \\ ${ }^{1}$ Ecole hôtelière de Lausanne, HES-SO // University of Applied Sciences Western Switzerland \\ ${ }^{2}$ IESE Business School, Universidad de Navarra, Barcelona, Spain \\ ${ }^{3}$ ESE Business School, Las Condes, Santiago de Chile \\ Correspondence: Maria Jose Bosch, ESE Business School, Av. Plaza 1905, Las Condes, Santiago de Chile. Tel: +562 \\ 2618 1535. E-mail: mjbosch.ese@uandes.cl
}

\author{
Received: May 11, 2016 \\ Accepted: May 19, $2016 \quad$ Online Published: June 7, 2016 \\ doi:10.5539/ibr.v9n8p24 \\ URL: http://dx.doi.org/10.5539/ibr.v9n8p24
}

\begin{abstract}
The purpose of this empirical study is to examine the conditions under which work-family enrichment happens. We conducted a total of 30 interviews with managers (and their spouses) participating in a demanding executive education program at a prestigious business school in Spain in order to explore how work and family resources are generated and transferred from one role to the other. Based on the qualitative results, we developed a model and surveyed 302 Chilean employees across an organization in the industrial sector in order to test our preliminary results in the qualitative stage. In our qualitative study, we find that there is a unique resource generated only in the family domain, which we define as "agape love" that contributes to enrichment. Our quantitative study confirms that, the more individuals experience agape love from spouse and children, the more the family enriches the employee's work life.
\end{abstract}

Keywords: work-family enrichment, agape love, resources, dual-career couples, employees, mixed-methods

\section{Introduction}

A growing number of studies in the work-family literature have focused on the positive interaction between work and family roles. According to seminal work by Greenhaus and Powell (2006), work can enrich family life and family can enrich work life. A large body of research shows evidence of the enrichment phenomenon. For instance, men with children are more satisfied and committed to their careers than men without children (Friedman \& Greenhaus, 2000).Women find psychological and emotional support in their personal lives. This support enables them to further develop interpersonal and leadership skills, which, in turn, enhance their effectiveness in management roles (Ruderman, Ohlott, Panzer, \& King, 2002). Parental commitment is associated with career satisfaction and performance, while marital commitment is linked with lower strain and higher career satisfaction and performance (Graves, Ohlott, \& Ruderman, 2007). Likewise, marital satisfaction is related to job satisfaction and marital discord to job dissatisfaction (Rogers \& May, 2003).

Despite increasing evidence of the enrichment phenomenon, we know little about why and how work and family enrich one another. This research gap might be explained by two main reasons. First, studies have extensively focused on the outcomes of work-family enrichment. Second, the lack of qualitative methods have limited our understanding of the process of this positive phenomenon. Deciphering the enriching mechanisms will help us to collectively advance the understanding of the process through which resources in one role accumulate and transfer from one role to the other.

Given this important research gap, the purpose of our empirical study is to examine the conditions that enable work-family enrichment. With this purpose in mind, we first conducted a total of 30 interviews with six dual-income couples with children in order to explore how work and family resources are generated and transferred from one role to the other. We then developed a model based on the qualitative results and surveyed 302 employees across an organization in the industrial sector in order to test our preliminary results. We used this two-step method, known also as the sequential exploratory mixed-methods approach, since this strategy is employed to help interpret qualitative results and test frameworks (Creswell, 2003). Combining these two data sources enables us to (a) explore the conditions under which work-family enrichment happens and (b) test whether resources generated in a role and enrichment are associated with the identified conditions.

Our study makes several contributions. First, it advances our knowledge of: (a) the factors that generate the resources to be transferred and (b) the conditions under which resources are transferred from one role to another. Second, our paper 
contributes to the literature on work-family by identifying and understanding the phenomenon not only from the perspective of the focal person but also from the perspective of the family, in this case a working spouse. Third, we respond to a call for more qualitative research. In fact, this paper adds to the current work-family literature, which accounts for approximately $10 \%$ of all papers published on this topic (Eby, Casper, Lockwood, Bordeaux, \& Brinley, 2005). In doing so, we contribute to a deeper understanding of the process of managing the work-family interface. Finally, we contribute to understanding the work-family phenomenon in a non-Anglo-Saxon context, which allows us to understand the phenomenon in a context underrepresented in the literature (see for example Poelmans et al., 2003).

\subsection{Core Concepts of Work-family Enrichment Theory}

Work-family enrichment (WFE) theory is grounded in the expansionist theories of Sieber (1974) and Marks (1977). Sieber's (1974) role accumulation theory posits that participation in multiple roles generates rewards such as role privileges, status security, status enhancement, and role performance personality enrichment and ego gratification. Thus, rewards acquired in one role as a by-product of social relationships may be reinvested in other roles. In a similar vein, Marks (1977) proposed that multiple roles are not only a source of strain but can also create energy that is used to enhance experiences in other roles.

Extending the work of Sieber (1974) and Marks (1977), Greenhaus and Powell (2006) define work-family enrichment as a process in which experiences in one domain (work or family) improve quality of life - understood as high performance and positive affect - in another domain (family or work). They propose that resources generated in one role and transferred to another role might include skills and perspectives, psychological and physical resources, social capital, flexibility (i.e. discretion to determine when and where to carry out role duties), and material resources. Individuals can transfer the resources if they perceive the latter as applicable and compatible with the demands of the receiving role (Weer, Greenhaus, \& Linnehan, 2010). An individual's positive affect can also trigger the transfer of resources and improve the receiving role (Siu et al., 2011).

\subsection{Past Research on Work-family Enrichment}

In their meta-analysis study, McNall, Nicklin, and Masuda (2010) show that work-family enrichment is associated with job satisfaction, affective commitment, and wellbeing. Lu (2011) shows that work resources lead to work-to-family enrichment, which in turn increases job satisfaction over time. This is also the case for family resources, family-to-work enrichment, and family satisfaction. Likewise, Hakanen and colleagues (2011) find that job resources, work-to-family enrichment, and work engagement reciprocally influence each other over time; they also find that family-to-work enrichment influences both home resources and marital satisfaction. Other outcomes resulting from enrichment include increased affective organizational commitment (Wayne, Randel, \& Stevens, 2006), and perception of psychological contract fairness (Taylor, DelCampo, \& Blancero, 2009), as well as lower turnover intentions (Russo \& Buonocore, 2012) and absenteeism (Brummelhuis, Hoeven, Jong, \& Peper, 2013).

An increasing number of studies on enrichment have also examined its antecedents and its role as a mediator mechanism. At the individual level, a person's identity and emotional support is related to increased enrichment (Wayne et al., 2006) and positive affectivity is associated with greater enrichment (Daniel \& Sonnentag, 2014; McNall, Scott, \& Nicklin, 2015). At the organizational and home level, work-life balance policies, work-family culture, job characteristics, and support from supervisor, peers, and family predict work-to-family enrichment while job characteristics and family support predict family-to-work enrichment (Baral \& Bhargava, 2011). Enrichment mediates, for instance, the relationship between schedule flexibility and both job satisfaction and family performance (Carlson, Grzywacz, \& Kacmar, 2010); between flexible work arrangements and both job satisfaction and turnover intentions (McNall, Masuda, \& Nicklin, 2010); between job characteristics and job outcomes (job satisfaction, organizational commitment and organizational citizenship behaviors).

Thus, the abovementioned body of literature has advanced our knowledge of what predicts enrichment, and what enrichment leads to, and its role as a mediating mechanism. Yet, we know little regarding the conditions under which enrichment occurs. Identifying the conditions that foster this enrichment is exactly what we seek to contribute with our research. Thus, in the first exploratory phase, we decided to conduct interviews in order to understand how resources are generated and transferred. To do this, we interviewed individuals in dual-income couples in Spain. We followed this initial phase with a survey in which we tested whether resources generated in a role and enrichment are associated with the identified conditions. To do so, we surveyed individuals in an organization in Chile. We selected these two countries because they are rather similar to each other in key dimensions, yet different enough from the USA and Germanic contexts, which provides a rather different research context from those that are usually represented in work-family research.

Spain and Chile share key socio-political features that are also common to the USA and Germany. For instance, Chile has an index of 0.967 in the Gender Equality Index and Spain 0.975. Thus, in this key feature these are countries that 
are quite similar to each other and similar to the USA and Germany, which have an index of 0.995 and 0.963 , respectively. Yet, while Spain and Chile share a common cultural and historical heritage, reflected in the same official language (Spanish) and the main religious beliefs (Catholicism), they are different from the USA and Germany. Also, the economic situations of Spain and Chile differ enormously from those of the USA and Germany. While the GNI (formerly GNP) in Germany was $\$ 47,590$ per capita and $\$ 55,230$ in the USA in 2014 , it was $\$ 14,910$ in Chile and $\$ 29,390$ in Spain. Thus, these two countries - which differ considerably from the Anglo-Saxon and Germanic contexts in which most work-family research has been conducted - present similarities that enable us to cluster them together. From previous studies on Ibero-American countries, we have evidence that differences in the country contexts influence the extent to which work-family enrichment occurs (Las Heras, Trefalt, \& Escribano, 2015), yet the basic relationships hold true across countries (Las Heras, Bosch, \& Raes, 2015).

\section{Qualitative Method}

\subsection{Sample and Procedure}

Enrichment occurs in a subtle and continuous manner, such that one cannot physically observe that a person's family life is enriched by his or her work life and vice-versa. Yet, it was important to ensure that our potential interviewees had experienced different levels of work-family enrichment, so that they would provide us with evidence of the factors that enabled various levels of enrichment. To this end, we surveyed 157 individuals participating in a demanding executive education program at a prestigious business school in Spain. We used the 22-item scale developed by Hanson, Hammer, and Colton (2006), e.g. "skills developed at work help me in my family life". We decided that for a person to be eligible as an interviewee, he or she had to be working full-time, living with a working spouse, and with at least one dependent child living with them. Among those who met these conditions, we decided to interview focal respondents and their spouses, since the role of family members in the enrichment process is bound to be relevant, and having data external to the focal person seemed to be key. We followed the diverse case selection method (Gerring, 2007) that led us to choose two individuals from each category, i.e. highest enrichment scores $(M=4.14, M=4.68)$, mid-range scores $(M=3.68$, $\mathrm{M}=3.77)$, and lowest scores $(\mathrm{M}=2.82, \mathrm{M}=3.14)$. All selected participants, and their spouses, agreed to participate in the study.

Each of these dual-income, heterosexual, couples completed a profile sheet containing demographic questions regarding their work and family life. All interviewees were Spanish except for one who was Peruvian. Of the focal respondents, five were men and one was a woman, which resembles the participants of the programs, made up of about $17 \%$ women. The average age was 39.7 and all had a university degree. The average work experience was 16.8 years. The average age of the spouses was 39.5 and three of them held a university degree. The average work experience was 15.5 years and all spouses except one worked full-time. On average, couples had been together for 16.5 years, and had between one and four children.

\subsection{Interviews}

We designed an interview questionnaire based on the WFE theoretical model, the literature, and experts' feedback. Prior to the main interviews, we conducted four pilot interviews with two married couples with dependent children to ensure respondents understood the questions and provided answers within the scope of our research question. We checked that questions were phrased in a way that would prevent social desirability. From the pilot interviews we identified a set of preliminary codes. By the fourth pilot interview, we had gathered enough data to create a set of relevant and clear questions to be asked in the main study.

Each of the six dual-income couples was interviewed five times (four single and one couple interview) for a total of 30 interviews ${ }^{1}$ (e.g. "Think about your work / family for a moment. What are the benefits you gain through your work / family? In your opinion, what has allowed you to gain these benefits?"). Interviews were face-to-face and were conducted in the respondent's office, home, or at the business school. Each interview took an average of one hour, for a total of 30 hours of interviews that were tape recorded and transcribed verbatim for analysis. Each couple received an executive summary of our findings and a $€ 100$ restaurant voucher to thank them for their participation.

\subsection{Analysis}

We conducted the data analysis in two stages. First, the lead author worked with two PhD students who acted as research assistants to produce a four- to five-page narrative summary for each couple. This process allowed us to comprehend and focus on the uniqueness of each couple as we aimed to preserve the stories (Riessman, 2008). In the second stage, we conducted a thematic analysis (Riessman, 2008). In this stage, the constructs of the WFE theory guided our analysis. We tried to preserve the stories "intact" while discovering common thematic elements across

\footnotetext{
${ }^{1}$ Please contact the corresponding author for the complete set of interview questions.
} 
interviews (sequence, time, and place). We cycled back and forth between data and theory as we compared emerging themes from the data to existing theory within and across interviews. We used Atlas.ti version 5.2 to manage our data.

More specifically, in the second stage of the analysis, the lead author and another $\mathrm{PhD}$ student, acting as a research assistant, independently conducted a line-by-line codification of the data of one couple. Together we generated 190 first-level codes, which were then reduced into more abstract second-level codes (48 of them) and subsequently grouped into categories and subcategories (Miles \& Huberman, 1994). This was compiled in a codebook with common themes and their descriptions, which were discussed and established between the two independent coders. Differences that emerged between the two coders were discussed with the participation of the second author until an agreement was reached. We coded the rest of the interviews based on the codebook, and during that stage we generated about 100 new first-level codes that we integrated into the codebook. It was evident that some themes were more salient than others because they appeared repeatedly in the data.

\subsection{Results}

\subsubsection{Factors Generating Work and Family Resources}

In line with WFE theory, participants' work and family roles generated resources such as skills and perspectives, flexibility, psychological and physical resources, and social capital. In our interviews, material resources that could be transferred to the other role (family) emerged only in the work role. Most importantly, we found a resource that is only generated in the family role. We labeled it agape love characterized by loving (and being loved by) others unconditionally, sacrificing oneself, and in a self-giving manner. The following quote exemplifies this resource: "Family makes you have more virtues, be less selfish, makes you love more, give more, and receive much more but you only realize it when you have them, because before having them, you don't really know what it means to have a spouse who loves you and children who love you for who you are." (wife, C5I1). "The love and care you receive is key, to have that trust that you can rely on someone, in my case it's my wife" (husband, C5I3). "The love you have for your own child is essentially different from any other kind of love" (husband, C3I2).

We found that organizational factors enhanced resources generated in the work role and home factors contributed to resources produced in the family role. The organizational factors that enhance resources generated in the work role are well-established constructs in the management literature. They include the nature of the job (task itself and job characteristics), hygienic factors (salary, interpersonal relations, working conditions, and work-life balance policies), and organizational structure (size and hierarchy of the company). The following quote illustrates the first two factors: "Well, the fact that I work for a lawyer's office means that it is a complex work, but also that I get a very satisfactory salary. On the other hand, since it is complex and very technical, it makes me feel good professionally too. At the same time, the people I get to meet for work reasons are very interesting because the clients are executives and my peers are excellent lawyers too" (wife, C1I3).

The home factors that contributed to resources generated in the family role are new to the literature. They include couple congruence, parenting experience, and share of caring responsibilities. Couple congruence refers to the extent spouses fit with one another in terms of life expectations, core values, personality traits, and professional profiles. Congruence not only implies being similar but also complementary as well. For instance, one of the respondents affirms: "My wife's understanding is key, because we have complementary qualities, complementary tastes. So, I do not have to justify every single thing I want to do, or every single decision I make regarding the home or the family. We considerably agree in the important things in life" (husband, C1I3).

Parenting experience consists of parenthood (being a mother or father), co-parenting (raising children with spouse), and the relationship with children. The following quote illustrates how parenting experience contributes to family resources: "As you see them growing, how they develop, how they become their own person, in each stage of life they contribute to you with different things. When they are still small they bring you novelty, their dependency on you. They give you the pleasure of educating and teaching them. When they grow a little older, there are the games, the comments, the reflections they make and they share with you their worries and concerns. When they grow mature you can think more with them" (wife, C2I2).

Finally, share of caring responsibilities refers to the extent to which childcare and household tasks are shared and managed by the couple (and external support, e.g., grandparents, nanny), and contribute to family resources as exemplified in this quote: "We decided one thing when we both had very similar jobs. We decided to - which is also one of the reasons why I did the MBA and not her because she could have done it too - we decided to create a family and it was clear to us that we could not possibly keep up with the same pace of work, around twelve to thirteen hours per day. When we had our first daughter, we still had this situation and it was very difficult. We needed much help from the grandparents and we also realized that our daughter was not reacting well. We were sad with this situation. We decided that one of us would lower the work expectations. This was my wife. Of course, this has definitely helped my career"'(husband, C6I3). 


\subsubsection{Conditions for Transfer of Resources}

We found that the decision to transfer resources from one role to another can be either deliberate, when individuals tap into the resources of one role when they are motivated to improve the other role, or unconscious, when individuals had had previous enrichment experiences. This is not surprising as unconscious thoughts, feelings, and behaviors are the drivers of daily life (Bargh, 2007) and represent a large part of daily behavior (Andersen, Moskowitz, Blair, \& Nosek, 2007). Thus, in our qualitative study we identified motivation and previous enrichment experience as conditions for transfer of resources.

Motivation is a set of psychological processes that directs, energizes, and sustains action (Ryan \& Deci, 2000). When the driving force behind an action is based on concern for others (prosocial motivation; Grant, 2007), it tends to facilitate work-to-family enrichment. When the motivation is an individual's interest or enjoyment (intrinsic motivation; Ryan \& Deci, 2000), it tends to facilitate family-to-work enrichment. An example of prosocial motivation is when individuals apply what they learn from work to better educate their children, to manage their home more effectively, or to maintain and improve the quality of life of family members. "With new knowledge that I obtain from work, I can contribute to the children with new things. When they come to me with a problem, I can help them. The more I know, the more I can help them, and the more I can teach them" (wife, C6I1).

An illustration of intrinsic motivation is when individuals consult their spouses in order to understand a particular topic related to their job in order to receive work-related advice or gain alternative explanations of a work situation. The following quote is from a school teacher who accepted managerial responsibilities. "They offered me to take it and I accepted, yet I didn't have any obligation to have an additional responsibility in the institute. For me it was a matter of personal development." The respondent sought advice from her husband regarding her new task: "Now I am responsible for the budget of the school and I sometimes need the help of my husband since he knows this topic" (wife, C3I1 and C3I3). In this representative case, family resources are transferred to the work domain to meet intrinsic motives, such as personal development and enjoyment.

Resources are also transferred from one domain to the other through previous enrichment experience. Once individuals experience the enrichment in Role B through Role A, they return to Role A seeking more of those benefits. The following quote shows how a respondent frequently consults his spouse for work-related support and advice. "When I finish work I always need someone with whom to unwind, someone who knows me and tries to understand where I come from. For me this is crucial. It helps me to keep balance. So, we talk a lot, she understands me very well, sometimes she offers me solutions and other times she offers me suggestions. I like having her opinion" (husband, C6I1).

The exploratory essence of the qualitative study highlighted the organizational and home factors essential to generate work-family resources. It also showed how they transfer from one domain to the other. In the second stage of our research, we quantitatively test the findings of our research that are new to the literature. In particular, we focus on agape love because it is a newly-identified resource specific to the family domain, and posit that love for the spouse and love from children will positively relate to family-to-work enrichment.

\section{Quantitative Method}

To develop our hypothesis, we draw from the broaden-and-build theory (Fredickson, 2001) which postulates that positive emotions (e.g. joy, love) broaden peoples' momentary thought-action repertoires. Furthermore, people who experience compassionate love (i.e. feelings, cognitions, and behaviors that are focused on caring, concern and tenderness towards others) engage in supportive behaviors because of enhanced sensitivity to the other person's distress (Collins et al., 2014). Thus, based on the broaden-and-build theory and on our findings in the qualitative stage, we hypothesize that the higher the focal person's perception of loving and being loved by the spouse and children, the more their family experiences will enrich their work life. We also propose that this relationship will be stronger when people are intrinsically motivated to do their work. We hypothesize based on our qualitative findings, that the more people find work rewarding in and of itself, the more they will be willing to bring resources acquired from the family domain to the workplace, to make their work even more satisfying. We also hypothesize that previous enrichment experience leads to increased enrichment, since it activates unconscious mechanisms that lead individuals to seek work resources in their family role.

\subsection{Sample and Procedure}

The second and third authors of this project were responsible for collecting quantitative data to test our hypothesized relationships. The third author contacted a Chilean company offering a final report as an incentive to participate in the study. All information given to the company was at the aggregate level. Questionnaires were administered in Spanish. The scale items from the questionnaire were translated from its original English version to Spanish using back translation (Brislin, 1986). The responses were collected either in paper or electronic format which had an identical layout. In total, 
605 employees were contacted that yielded 302 responses (49.9 percent response rate). The final sample included 96 percent male and the average age was 48 years $(\mathrm{SD}=9.28)$. The average tenure was 7.7 years $(\mathrm{SD}=6.3)$. The majority of respondents had children (71 percent) and were in a romantic relationship (77.5 percent).

\subsection{Measures}

\subsubsection{Family-to-work Enrichment (FWE)}

To measure FWE, we used Stanko's (2011) four-item measure. Consistent with our conceptualization - and unlike other measures of enrichment (e.g., Carlson, Kacmar, Wayne, \& Grzywacz, 2006) - this four-item scale measures an experience that may improve performance in the receiving role but does not necessarily do so. An example is, "Fulfilling my work responsibilities has enriched the interpersonal skills I need to succeed at home" and are rated on a seven-point scale $(1=$ totally disagree to $7=$ totally agree). The four items were averaged to create a scale score $(\alpha=0.94)$.

\subsubsection{Love from Spouse (LFS)}

To measure LFS, we adapted four items from the short form of the love attitudes scale developed by Hendrick, Hendrick, and Dicke (1998). Sample items include, "My partner is usually willing to sacrifice his / her own wishes to let me achieve mine", and "My partner would endure all things for my sake". Each item consists of a seven-point scale (1=totally disagree to $7=$ totally agree). The four items were averaged to create a scale score $(\alpha=0.90)$.

\subsubsection{Love for Children (LFC)}

To measure LFC, we adapted three items from the short form of the love attitudes scale developed by Hendrick et al. (1998). Sample items include, "I would rather suffer myself than let my child / children suffer", and "I cannot be happy unless I place my child's / children's happiness before my own". Each item consists of a seven-point scale (1=totally disagree to $7=$ totally agree). The three items were averaged to create a scale score $(\alpha=0.76)$.

\subsubsection{Past Experience of Enrichment (PEE)}

To measure PEE, we use two questions developed for this study: "I can think of instances when experiences at home helped me to be more effective in my job" and "I remember situations when the advice I've received at home has helped me to be more effective in my job". Each item consists of a seven-point scale (1=totally disagree to 7=totally agree). The two items were averaged to create a scale score $(\alpha=0.85)$.

\subsubsection{Intrinsic Motivation (IM)}

To measure IM, we used a four-item scale developed by Grant (2008). The person is asked "Why are you motivated to do your work?" Sample items include "Because I enjoy the work itself", and "Because I learn/develop competencies". Each item consists of a seven-point scale ( $1=$ totally disagree to $7=$ totally agree). The four items were averaged to create a scale score $(\alpha=0.90)$.

\subsubsection{Control Variables}

Single items were used to measure employees' children (no $=0$, yes 1 ), relationship status (not in a relationship $=0$, in a relationship=1), age, gender (male $=0$, female $=1$ ), tenure, the number of hours spent with children during a normal working day and if the employee's parents or parents-in-law live at their house (yes $=1$, no $=0$ ).

\subsection{Analysis}

We tested our model in three interlinked steps. First, we tested the direct relationship between love from spouse (LFS) and family-to-work enrichment (FWE), and love for children (LFC) and family-to-work enrichment (FWE) through a regression. Once we established these relationships, we tested the moderating effect of past enrichment experience (PEE) and intrinsic motivation (IM) over the relationship between LFS and FWE, and LFC and FWE. We tested the two moderating effects through a regression. Finally, we tested the two models together. We used STATA 13 (Rabe-Hesketh \& Skrondal, 2008) software packages for data analysis.

\subsection{Quantitative Results}

The descriptive statistics of our main variables are in Table 1. All Cronbach alphas are above the acceptable level for the number of items (Cortina, 1993). 
Table 1. Descriptive Statistics and Correlations

\begin{tabular}{|c|c|c|c|c|c|c|c|c|c|c|c|c|c|c|}
\hline & Variable & Mean & Alpha & 1 & 2 & 3 & 4 & 5 & 10 & 11 & 12 & 13 & 14 & 15 \\
\hline 1 & FWE & 5.67 & 0.94 & 1.00 & & & & & & & & & & \\
\hline 2 & LFS & 4.59 & 0.9 & $0.13 * *$ & 1.00 & & & & & & & & & \\
\hline 3 & LFC & 6.22 & 0.76 & $0.18 * * *$ & $0.31 * * *$ & 1.00 & & & & & & & & \\
\hline 4 & PEE & 5.83 & 0.85 & $0.57 * * *$ & $0.12 * *$ & $0.18^{* * *}$ & 1.00 & & & & & & & \\
\hline 5 & $\mathrm{IM}$ & 5.83 & 0.9 & $0.60 * * *$ & 0.07 & $0.11^{*}$ & $0.38^{* * * *}$ & $* 1.00$ & & & & & & \\
\hline 10 & Age & 37.5 & & -0.08 & -0.06 & 0.06 & -0.10 & -0.07 & 1.00 & & & & & \\
\hline 11 & Gender & 1.04 & & 0.02 & -0.04 & -0.1 & 0.07 & 0.02 & $0.18 * *$ & 1.00 & & & & \\
\hline 12 & Elder in the house & 0.68 & & 0.00 & 0.00 & -0.02 & -0.06 & -0.04 & 0.11 & -0.01 & 1.00 & & & \\
\hline 13 & Tenure & 7.8 & & 0.03 & 0.03 & 0.14 & 0.08 & 0.05 & -0.02 & -0.06 & $-0.30 * *$ & 1.00 & & \\
\hline 14 & Children & 0.71 & & 0.07 & 0.01 & 0.08 & $0.11^{* *}$ & 0.05 & $-0.38 * *:$ & -0.09 & -0.06 & -0.02 & 1.00 & \\
\hline 15 & Relationship & 0.77 & & 0.04 & 0.03 & 0.02 & 0.00 & 0.02 & $-0.19 * *:$ & 0.10 & 0.00 & 0.03 & $0.10 *$ & 1.00 \\
\hline 16 & Number of hours & 2.96 & & 0.08 & -0.01 & -0.01 & $0.14 * *$ & $0.12 *$ & 0.02 & 0.13 & -0.17 & $0.19^{*}$ & 0.09 & -0.05 \\
\hline
\end{tabular}

$* \mathrm{p}>0.1$

$* * \mathrm{p}>0.05$

$* * * \mathrm{p}>0.01$

We multiply love from spouse (LFS) with "relationship" in order to include only respondents who report being in a relationship. Also, we multiply love for children (LFC) by "children" in order to include only people with children, this multiplication generated 265 responses. We tested the direct relationship between LFS and family-to-work enrichment (FWE), and between LFC and family-to-work enrichment (FWE). Our exploratory analysis showed that there is a positive relationship between LFS and FWE $(B=0.09, S E=0.04, p<0.05)$, and also between $\mathrm{LFC}$ and $\mathrm{FWE}(\mathrm{B}=0.16, \mathrm{SE}=0.05$, $\mathrm{p}<0.001)$.

Then, we tested the moderating effect of intrinsic motivation (IM) and past enrichment experience (PEE) on the relationship between LFS and FWE, and between LFC and FWE. To check these relationships we tested the direct effect and we also built interaction terms (Aiken \& West, 1991). Results for the first model (a) show a positive relationship between LFS and FWE $(B=0.43, S E=0.23, p<0.1)$, also a positive effect of IM $(B=0.59, S E 0.18, p<0.01)$, but no moderating effect of IM (on the relationship between LFS and FWE. Also, results show a positive effect of PEE (B=0.41, $\mathrm{SE}=0.16, \mathrm{p}<0.01)$ and no moderating effect of PEE on the relationship between LFS and FWE. The fit tests are satisfactory for this model $\mathrm{F}(11,50)=254.86, \mathrm{p}<0.001$.

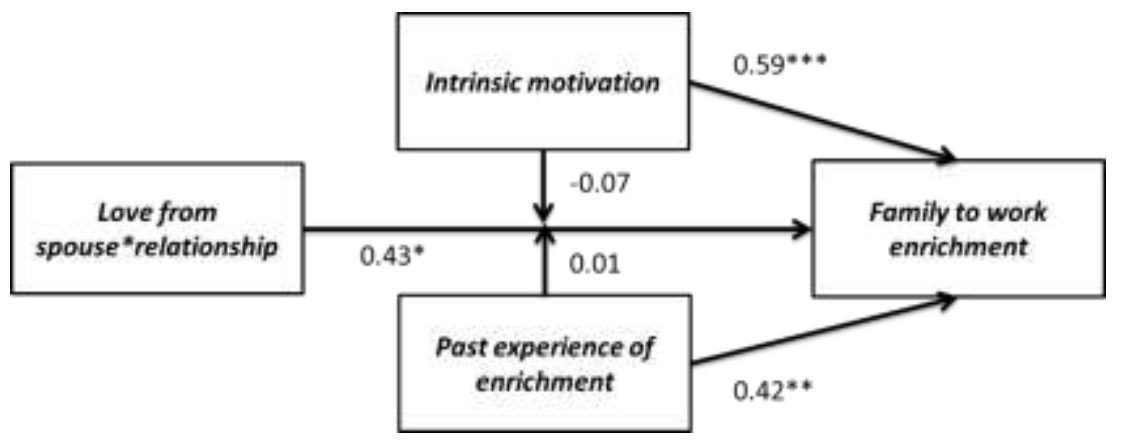

Figure 1. Model (a)

The results for our second model (b) show a positive relationship between $\mathrm{LFC}$ and $\mathrm{FWE}(\mathrm{B}=0.45, \mathrm{SE}=0.26, \mathrm{p}<0.1)$, also a positive effect of IM $(B=0.80, S E=0.26, p<0.01)$ and a moderating effect of IM on the relationship between LFC and FWE $(B=-0.08, S E=0.04, p<0.05)$. Also, model (b) results show a positive direct effect of $\mathrm{PEE}(\mathrm{B}=0.42, \mathrm{SE}=0.18, \mathrm{p}<0.1)$ and moderating effect of PEE on the relationship between LFC and FWE (see Figures 1, 2, and 3). The control variable, i.e. the number of hours the employee usually spends with his or her children during a normal working day, has a small and negative effect on FWE; all other control variables are not significant. The fit test are satisfactory for this model $\mathrm{F}$ $(12,51)=244.27, \mathrm{p}<0.001$. 


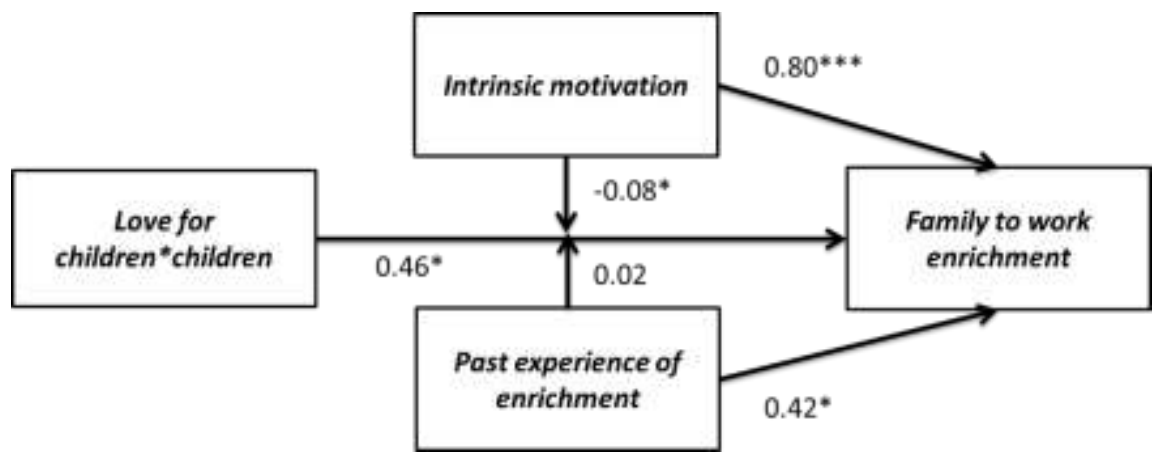

Figure 2. Model (b)

Finally, we included all variables of both models. Results in Table 2 show that there is a significant effect of LFS on FWE $(B=0.51, S E=0.23, p<0.05)$ and that there is also a significant effect of LFC on FWE $(B=0.48, S E=0.25, p<0.1)$. Results also show a positive effect of IM $(B=1.28, S E=0.32, p<0.01)$ and a moderating effect of IM on the relationship between LFS and FWE $(B=-0.10, S E=0.06, p<0.05)$, and a moderating effect of IM on the relationship between LFC and FWE $(\mathrm{B}=-.11, \mathrm{SE}=0.04, \mathrm{p}<0.1)$. Finally, results in table 2 show no direct or moderating effect of PEE. The control variable, i.e. the number of hours the employee usually spends with his or her children during a normal working day, has a small and negative effect on FWE, all other control variables are not significant. The fit test are satisfactory for this model $\mathrm{F}(15,46)$ $=200.40, \mathrm{p}<0.001$.

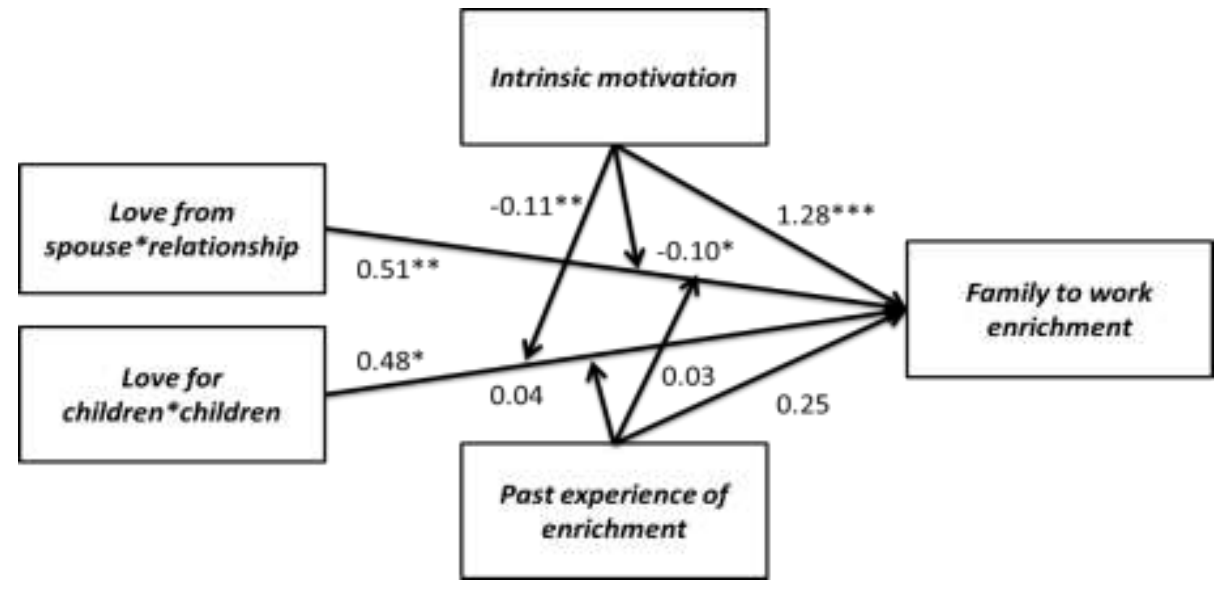

Figure 3. Model (c)

On the one hand, our results show that IM has a strong effect over WFE, stronger than LFS and LFC. When we compare our three models, results show that changes in IM have the highest impact over WFE. On the other hand, our results show that PEE has an effect over WFE only when we examine the effect of LFS and LFC over WFE separately; when we examine the effect of LFS and LFC over WFE together IM becomes the strongest variable and PEE is no longer significant. 
Table 2. Path Coefficients for Relationships in Research Model

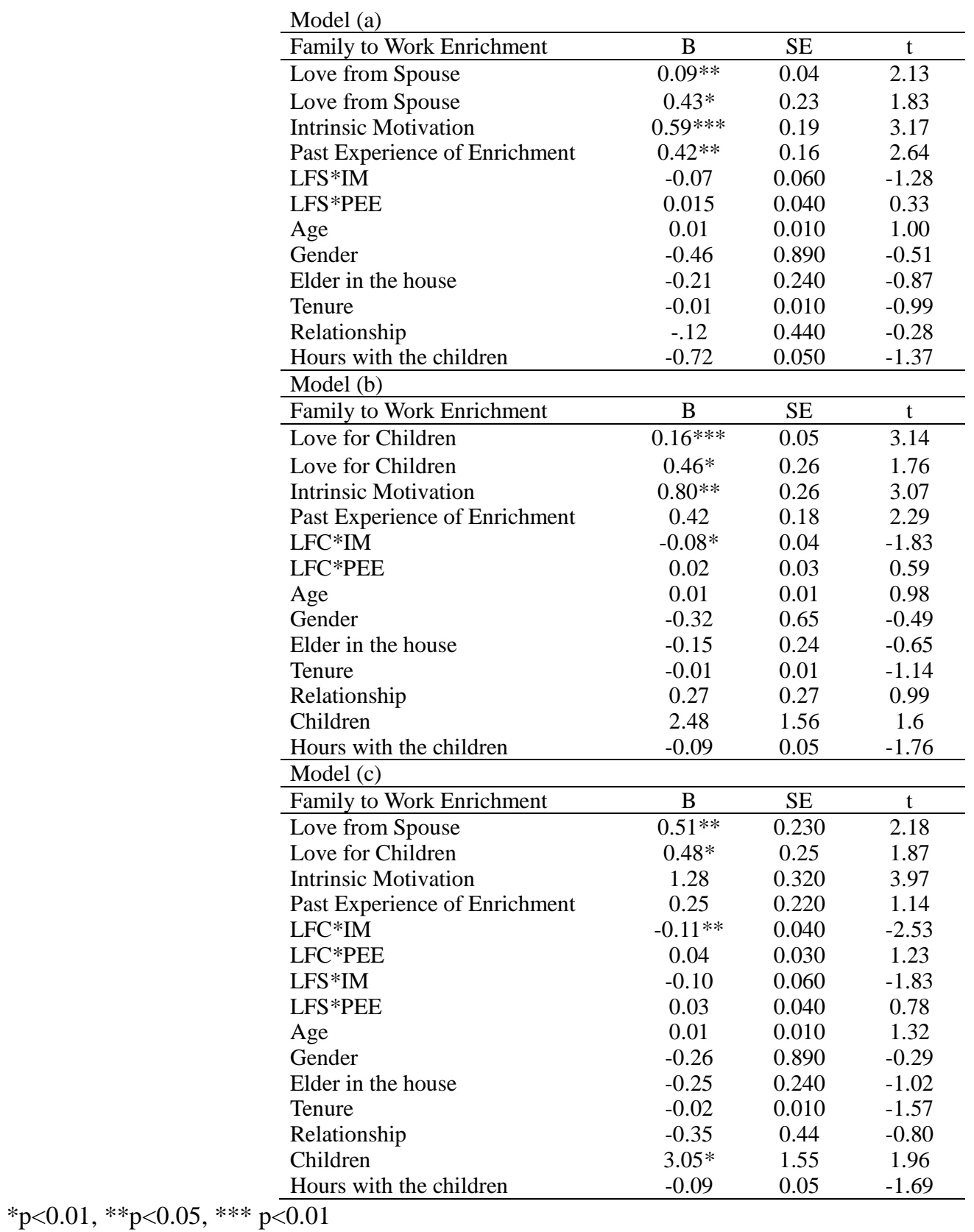

\section{General Discussion}

The aim of the present study was to examine the conditions under which enrichment happens. To achieve this goal we pursued our research in an Ibero-American environment. First, we conducted an exploratory study that consisted of 30 interviews with six dual-income couples with children in Spain. From the findings, we developed a model that was tested on 302 employees of an organization located in Chile.

Our study revealed a resource exclusive to the family domain: agape love, which predicts family-to-work enrichment as supported by our quantitative study. Agape love is distinct from psychological and physical resources (e.g., having self-esteem because spouse values him/her) and social capital resources (e.g., information benefits acquired by consulting his/her spouse). Moreover, love - as presented in this study - is beyond affect. Individuals might establish affective bonds resulting in friendship or professional relations with high-quality connections (Dutton \& Heaphy, 2003). However, marital love entails exclusivity and a long-term perspective. Both marital and children's love entails thinking about the other first, and the desire to sacrifice oneself for the other. While agape love has an affective dimension, affect is not equivalent to it, as love also entails a cognitive dimension, i.e. the rational decision to love (Argandoña, 2011). Interestingly, we found that love from the spouse predicts family-to-work enrichment to a greater extent than love for 
children. An explanation of this might be that spouses (more than children vis-à-vis their parents) who love their partners are mature enough to understand and empathize with (and take action if necessary) their partner's needs, thoughts, feelings and behaviors. Future research should examine more closely the effects of this critical dimension of family relationships on enrichment, which might also help explain why most studies find that family-to-work enrichment is substantially stronger than work-to-family enrichment (Greenhaus \& Powell, 2006). Focusing on family and improving our knowledge of how family affects work is crucial for a field of research that claims to study work and family, yet predominantly focuses on work.

In addition, our paper demonstrates that factors that generate resources obtained from work and family roles differ. Organizational factors include the nature of the job, hygienic factors, and organizational structure. Home factors include couple congruence, parenting experience, and share of caring responsibilities. A main difference between the factors in these two domains is that home factors are inherently relational. This does not mean that a person can neglect the relational aspect at work. However, interpersonal relations are but one of the organizational categories of factors contributing to work resources, while, at home, the relationships with spouse, children and potentially other family members these relations account for the entirety of the family domain. Hence, relations with family members might be of critical importance because there are no "substitutes" as in the case of work. Future research should seek to understand the extent to which various relationships, with children, parents, and extended family, specifically contribute to enrichment. Also, although this research focused on family members, societal roles are also of importance and should be further studied.

Finally, our qualitative study shows that resources are transferred deliberately by those who are motivated intrinsically by their jobs. However, even if there is a lack of intention to transfer resources enrichment can still happen, via unconscious processes or else under the condition that there has been previous enrichment experience. Our quantitative study partially supported these findings. We find a negative moderating effect of intrinsic motivation on love for children and family-to-work enrichment. We also find a negative moderating effect of intrinsic motivation on love from spouse and family-to-work enrichment. That is, when individuals are highly energized by intrinsic motives, love in the family is less relevant in making a difference at the workplace. Yet, there is a strong direct relationship between intrinsic motivation and family-to-work enrichment. In other words, to intrinsically-motivated individuals, love for children and from the spouse might somehow deter them from spending a disproportionate amount of resources in work endeavors. Since respondents in our sample were only able to refer to conscious processes, this might mean that love from spouse and for children might lead to higher conscious enrichment yet to lower overall enrichment. Thus, future research should contribute to a better understanding of unconscious vs. conscious mechanisms.

Regarding past enrichment experience, we did not find any moderating effect of it on love from spouse and family-to-work enrichment nor did we find a moderating effect of experience on love for children and family-to-work enrichment. In order to enrich their work life, individuals do not necessarily rely on past experiences. Rather, the extent to which they experience love at home is a more important factor. Again, future research might need to differentiate better between conscious vs. unconscious paths of enrichment.

\subsection{Implications for Practice}

Managers who seek to enable employees to improve their skills should realize that resources can be transferred from the home to the workplace. Thus, encouraging employees to spend quality time with family and enabling them to take advantage of family support policies might not only help individuals to manage work and family demands better but also experience love to a greater extent, which will lead to greater family-to-work enrichment. Thus, it turns out that love is good for business.

Organizations interested in promoting work-family balance should include in their family-friendly policies training on WFE and the importance of the proactivity of individuals in this process. In particular, organizations should offer training to their managers so they understand the extent to which employees' family life and resources can enhance their work resources. One of the key reasons formal policies are not used in companies tends to be managerial reluctance to let employees use them. The more managers understand and value the importance of their employees' home life for work, the more they will foster their ability to experience enrichment.

\subsection{Limitations of Current Study}

As with any research, this study is not without limitations. First, the sample size of the qualitative study was modest. However, the cases included in the sample were carefully selected through a demanding process to ensure the quality of data. Then, the interviewees were intensively interviewed, both individually and together with their spouses who were interviewed separately as well. Thus, the authors made an explicit trade-off and opted to conduct in-depth analyses of fewer, but carefully selected, cases. 
Another limitation affecting the study's results was our qualitative sample profile, which consisted of highly-educated people with relatively well-paid jobs. As we were interested in dual-income couples, we selected participants with extremely demanding work and family situations. Thus, the findings of our study might not reflect enrichment processes in households with different conditions such as being a single parent or other samples, e.g., lower education level, blue-collar jobs, etc. This calls for more research with other samples before moving to a quantitative stage. Moreover, the nature of our quantitative sample might also be considered a source of limitations as all data is self-reported. Future research should include responses from employees, their spouses, and/or other family members.

\section{References}

Aiken, L. S., \& West, S. G. (1991). Multiple regression: Testing and interpreting interactions. Thousand Oaks, CA: Sage. http://dx.doi.org/10.1177/109821409301400208

Andersen, S. M., Moskowitz, G. B., Blair, I. V., \& Nosek, B. A. (2007). Automatic thought. In A. W. Kruglanski, \& E. T. Higgins (Eds.), Social psychology: Handbook of basic principles (pp. 138-175). New York, NY: Guilford Press.

Argandoña, A. (2011). Beyond contracts: Love in firms. Journal of Business Ethics, 99, 77-85. http://dx.doi.org/10.1007/s10551-011-0750-z

Baral, R., \& Bhargava, S. (2011). Examining the moderating influence of gender on the relationships between work-family antecedents and work-family enrichment. Gender in Management: An International Journal, 26(2), 122-147. http://dx.doi.org/10.1108/17542411111116545

Bargh, J. A. (2007). Social psychology and the unconscious: The automaticity of higher mental processes. New York, NY: Psychology Press.

Brislin, R. W. (1986). The wording and translation of research instruments. Beverly Hills, CA: Sage.

Brummelhuis, L. L., Hoeven, C. L., Jong, M. D. T., \& Peper, B. (2013). Exploring the linkage between the home domain and absence from work: Health, motivation, or both? Journal of Organizational Behavior, 34(3), 273-290. http://dx.doi.org/10.1002/job.1789

Carlson, D. S., Grzywacz, J. G., \& Kacmar, M. K. (2010). The relationship of schedule flexibility and outcomes via the work-family interface. Journal of Managerial Psychology, 25(4), 330-355. http://dx.doi.org/10.1108/02683941011035278

Carlson, D. S., Kacmar, M. K., Wayne, J. H., \& Grzywacz, J. G. (2006). Measuring the positive side of the work-family interface: Development and validation of a work-family enrichment scale. Journal of Vocational Behavior, 68(1), 131-164. http://dx.doi.org/10.1016/j.jvb.2005.02.002

Collins, N. L., Kane, H. S., Metz, M. A., Cleveland, C., Khan, C., Winczewski, L., Bowen, J., \& Prok, T. (2014). Psychological, physiological, and behavioral responses to a partner in need: The role of compassionate love. Journal of Social and Personal Relationships, 31(5), 601-629. http://dx.doi.org/10.1177/0265407514529069

Cortina, J. M. (1993). What is coefficient alpha? An examination of theory and applications. Journal of Applied Psychology, 78(1), 98-104. http://dx.doi.org/10.1037/0021-9010.78.1.98

Creswell, J. W. (2003). Research design: Qualitative, quantitative, and mixed-methods approaches. Thousand Oaks, CA: Sage publications.

Daniel, S., \& Sonnentag, S. (2014). Work to non-work enrichment: The mediating roles of positive affect and positive work reflection. Work \& Stress, 28(1), 49-66. http://dx.doi.org/10.1080/02678373.2013.872706

Dutton, J., \& Heaphy, E. (2003). The power of high-quality connections at work. In K. Cameron, J. Dutton, \& R. E. Quinn (Eds.), Positive Organizational Scholarship (pp. 263-278). San Francisco, CA: Berrett-Koehler Publishers.

Eby, L. T., Casper, W. J., Lockwood, A., Bordeaux, C., \& Brinley, A. (2005). Work and family research in IO/OB: Content analysis and review of the literature. Journal of Vocational Behavior, 66, 124-197. http://dx.doi.org/10.1016/j.jvb.2003.11.003

Fredickson, B. L. (2001). The role of positive emotions in positive psychology: The broaden-and-build theory of positive emotions. American Psychologist, 56(3), 218-226. http://dx.doi.org/10.1037/0003-066x.56.3.218

Friedman, S., \& Greenhaus, J. (2000). Work and family - allies or enemies? What happens when business professionals confront life choices. New York, NY: Oxford University Press.

Gerring, J. (2007). Case study research: Principles and practices. Cambridge, MA: Cambridge University Press.

Grant, A. M. (2007). Relational job design and the motivation to make a prosocial difference. Academy of Management Review, 32, 393-417. http://dx.doi.org/10.5465/amr.2007.24351328 
Grant, A. M. (2008). Does intrinsic motivation fuel the prosocial fire? Motivational synergy in predicting persistence, performance, and productivity. Journal of Applied Psychology, 93(1), 48-58. http://dx.doi.org/10.1037/0021-9010.93.1.48

Graves, L. M., Ohlott, P. J., \& Ruderman, M. N. (2007). Commitment to family roles: Effects on managers' attitudes and performance. Journal of Applied Psychology, 92(1), 44-56. http://dx.doi.org/10.1037/0021-9010.92.1.44

Greenhaus, J. H., \& Powell, G. N. (2006). When work and family are allies: A theory of work-family enrichment. Academy of Management Review, 31(1), 72-92. http://dx.doi.org/10.5465/amr.2006.19379625

Hakanen, J. J., Peeters, M. C., \& Perhoniemi, R. (2011). Enrichment processes and gain spirals at work and at home: A 3-year cross-lagged panel study. Journal of Occupational and Organizational Psychology, 84, 8-30. http://dx.doi.org/10.1111/j.2044-8325.2010.02014.x

Hanson, G. C., Hammer, L. B., \& Colton, C. L. (2006). Development and validation of a multidimensional scale of perceived work-family positive spillover. Journal of Occupational Health Psychology, 11, 249-265. http://dx.doi.org/10.1037/1076-8998.11.3.249

Hendrick, C., Hendrick, S. S., \& Dicke, A. (1998). The love attitudes scale: Short form. Journal of Social \& Personal Relationships, 15(2), 147-159. http://dx.doi.org/10.1037/t00409-000

Las Heras, M., Bosch, M. J., \& Raes, A. M. L. (2015). Sequential mediation among family friendly culture and outcomes. Journal of Business Research, 68(11), 2366-2373. http://dx.doi.org/10.1016/j.jbusres.2015.03.042

Las Heras, M., Trefalt, S., \& Escribano, P. I. (2015). How national context moderates the impact of family-supportive supervisory behavior on job performance and turnover intentions. Management Research: Journal of the Iberoamerican Academy of Management, 13(1), 55-82. http://dx.doi.org/10.1108/mrjiam-06-2014-0556

Lu, L. (2011). A Chinese longitudinal study on work/family enrichment. Career Development International, 16(4), 385-400. http://dx.doi.org/10.1108/13620431111158797

Marks, S. R. (1977). Multiple roles and role strain: Some notes on human energy, time and commitment. American Sociological Review, 42, 921-936.

McNall, L. A., Masuda, A. D., \& Nicklin, J. M. (2010). Flexible work arrangements, job satisfaction, and turnover intentions: The mediating role of work-to-family enrichment. The Journal of Psychology, 144(1), 61-81. http://dx.doi.org/10.1080/00223980903356073

McNall, L. A., Nicklin, J. M., \& Masuda, A. D. (2010). A meta-analytic review of the consequences associated with work-family enrichment. Journal of Business \& Psychology, 25, 381-396. http://dx.doi.org/10.1007/s10869-009-9141-1

McNall, L. A., Scott, L. D., \& Nicklin, J. M. (2015) Do positive affectivity and boundary preferences matter for work-family enrichment? A study of human service workers. Journal of Occupational Health Psychology, 20(1), 93-104. http://dx.doi.org/10.1037/a0038165

Miles, M. B., \& Huberman, A. M. (1994). Qualitative Data Analysis. Thousand Oaks, CA: Sage Publications.

Poelmans, S., Spector, P. E., Cooper, C. L., Allen, T. D., O'Driscoll, M., \& Sanchez, J. I. (2003). A cross-national comparative study of work/family demands and resources. International Journal of Cross Cultural Management, 3 , 275-288. http://dx.doi.org/10.1177/1470595803003003002

Rabe-Hesketh, S., \& Skrondal, A. (2008). Multilevel and longitudinal modeling using stata. College Station, TX: Stata Press.

Riessman, C. K. (2008). Narrative methods for the human sciences. Thousand Oaks, CA: Sage Publications.

Rogers, S. J., \& May, D. C. (2003). Spillover between marital quality and job satisfaction: Long-term patterns and differences. Journal of Marriage and Family, 65(2), 483-495. http://dx.doi.org/10.1111/j.1741-3737.2003.00482.x

Ruderman, M. N., Ohlott, P. J., Panzer, K., \& King, S. N. (2002). Benefits of multiple roles for managerial women. Academy of Management Journal, 45(2), 369-386. http://dx.doi.org/10.2307/3069352

Russo, M., \& Buonocore, F. (2012). The relationship between work-family enrichment and nurse turnover. Journal of Managerial Psychology, 27(3), 216-236. http://dx.doi.org/10.1108/02683941211205790

Ryan, R. M., \& Deci, E. L. (2000). Intrinsic and extrinsic motivations: Classic definitions and new directions. Contemporary Educational Psychology, 25, 54-67. http://dx.doi.org/10.1006/ceps.1999.1020

Sieber, S. D. (1974). Toward a theory of role accumulation. American Sociological Review, 39, 567-578. 
http://dx.doi.org/10.2307/2094422

Siu, O., Lu, J., Lu, C., Wang, H., Brough, P., Timms, C., Bakker, A., Kalliath, T., \& O'Driscoll, M. (Eds.). (2011). Testing a model of work-family enrichment: The effects of social resources and affect. San Antonio, TX: Academy of Management Annual Meeting Proceedings.

Stanko, T. L. (2011). From scout master to CEO: How participation in multiple roles shapes behavior at work. Oregon, OR: University of Oregon.

Taylor, B. L., DelCampo, R. G., \& Blancero, D. M. (2009). Work-family conflict/facilitation and the role of workplace supports for U.S. Hispanic professionals. Journal of Organizational Behavior, 30(5), 643-664. http://dx.doi.org/10.1002/job.605

Wayne, J. H., Randel, A. E., \& Stevens, J. (2006). The role of identity and work-family support in work-family enrichment and its work-related consequences. Journal of Vocational Behavior, 69(3), 445-461. http://dx.doi.org/10.1016/j.jvb.2006.07.002

Weer, C. H., Greenhaus, J. H., \& Linnehan, F. (2010). Commitment to non-work roles and job performance: Enrichment and conflict perspectives. Journal of Vocational Behavior, 76(2), 306-316. http://dx.doi.org/10.1016/j.jvb.2009.07.003

\section{Copyrights}

Copyright for this article is retained by the author(s), with first publication rights granted to the journal.

This is an open-access article distributed under the terms and conditions of the Creative Commons Attribution license (http://creativecommons.org/licenses/by/3.0/). 